\title{
Tianjin chemical clean-up after explosion
}

A massive clean-up of contaminated water is underway in the aftermath of the Aug. 12 chemical explosion in the port city of Tianjin, China that killed 114 people and injured more than 700; 69 people are still missing.

The crater left behind by the explosion quickly filled with 40000 tons of highly contaminated water that authorities now have to contain and dispose of safely.

On Aug. 17, high levels of dangerous chemicals were evident in 8 out of 76 area water samples, according to Bao Jingling, chief engineer from the Tianjin Environmental Protection Bureau. According to Xinhua News Agency, the site with the highest count exceeded acceptable levels by 28.4 times and included sodium cyanide, an extremely toxic chemical.

By Aug. 20, it was reported that the highest concentration of toxins was 356 times above the acceptable limit, according to Weiyong Tian, director of the Emergency and Accident Investigation Center, Ministry of Environmental Protection.

The Aug. 12 explosion occurred at a warehouse containing 40 types of chemicals, including 700 tons of highly toxic substances, mostly sodium cyanide, according to reports from state media. The cause of the explosion is not yet known. In addition to the human toll, it damaged 17000 homes and 170 businesses.

On Aug. 15, everyone within three kilometres of the blast was evacuated because of concerns over possible exposure to toxic contaminants.

More than 4000 medical staff at 38 local hospitals are still working to respond to the influx of injured residents, according to the National Health and Family Planning Commission of the People's Republic of China.

The Chinese newspaper, Nanfang Daily, reported that the emergency response at the hospital closest to the explosion reached peak levels in the

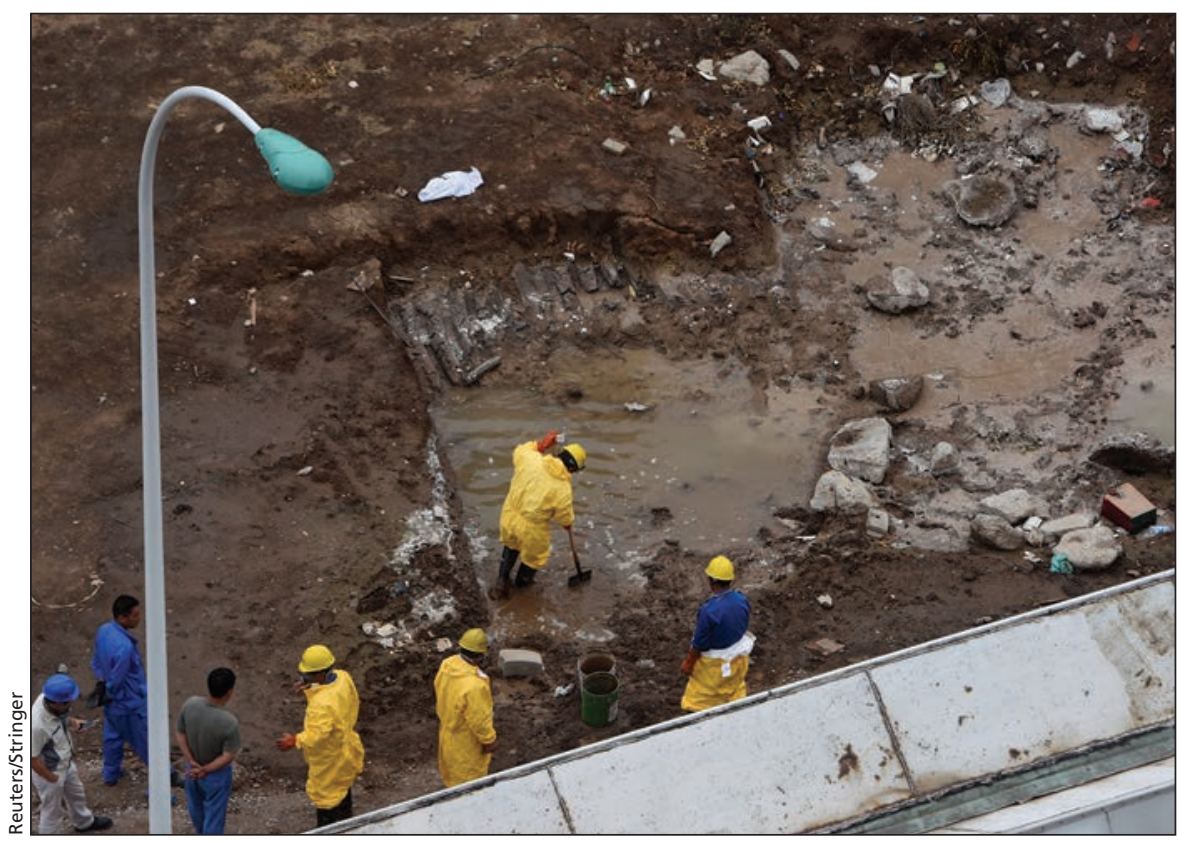

Rescue workers remove contaminated water from the explosion site in Tianjin on Aug. 19.

first hour and a half after the blast. By the next morning, Taida Hospital was caring for more than 400 patients, most of whom were suffering burns.

As of Aug. 20, 674 people were hospitalized and 108 released in Tianjin.

Despite the findings of highly toxic substances at the explosion site, the president of Taida Hospital told Global Times that if there were serious levels of toxic chemicals present, people would have already died.

The United Nations' top expert on the implications for human rights of hazardous substances called the lack of information "truly tragic." Special Rapporteur Baskut Tuncak called on the government of China and relevant businesses to ensure complete transparency in the investigation, including into the causes and effects of the explosion.

Tuncak underscored that "information about hazardous substances must be available and accessible in order to protect and respect the rights to life, health, meaningful public participation and an effective remedy, as well as freedoms of expression and the press."
Volunteer Yuxi Ying, who helped with the clean-up, wrote on Weibo, the Chinese version of Twitter, that some volunteers had experienced vomiting and trouble breathing three days after the explosion. She wanted a computed tomographic scan and blood test, but could only afford the latter. After receiving the blood test results, her doctor told her to go home and rest, adding that there was no specific treatment for possible poisoning from the blast.

In terms of air quality, the Tianjin Environmental Monitoring Centre reported no abnormalities among its 12 air-quality monitoring locations within a two-kilometre radius of the blast site. Wurui Wen, chief of the Tianjin Environmental Protection Bureau, said they had not detected any hydrogen cyanide gas so far.

Based on our analysis, it won't have an obvious impact to humans, he said. - Fangliang Xu, Joseph Paul Webb, Ottawa, Ont.

CMAJ 2015. DOI:10.1503/cmaj.109-5133 